\title{
蛙 \\ NeuroRehab \\ News \\ Uso de la Realidad Virtual y el Biofeedback \\ Realidad Virtual en niños con cefalea crónica
}

\section{Resumen:}

- dolor de cabeza o la cefalea es una patología frecuente entre la población adul-
var una vida "normal" ya que les reduce de manera significativa la calidad de vida.
Las propuestas de tratamiento siguen siendo los fármacos, sin embar-
go, en niños, hay una necesidad importante de desarrollar otros tipos de ter-
apia para que les resulten más atractivas y se adhieran mejor al tratamiento.
La realidad virtual y el biofeedback podrían considerarse como posible opción terapéutica para
abordar las cefaleas crónicas entre la población infantil. Hasta el momento se han encontra-

La cefalea es una de las patologías crónicas que se encuentran con más asiduidad entre la población infantil, considerándose el síntoma neurológico más frecuente y la manifestación de dolor más común en la infancia.

Las medidas de tratamiento que se consideran en la actualidad incluyen tanto tratamiento farmacológico (analgésicos, triptanes, ...) como no farmacológico (cambios en el estilo de vida, manejo del estrés y otras terapias de tipo conductual). Debido a que el abuso de medicación puede causar cefalea, se está intentando disminuir el uso de fármacos y proponer nuevas opciones de tratamiento no-farmacológicas.

Hasta el momento se han llevado a cabo varios estudios científicos donde se ha comprobado que el biofeedback y las imágenes guiadas mediante realidad virtual pueden considerarse opciones de tratamiento válidas para las cefaleas. Estas técnicas, presentan su efectividad principalmente en la reducción de la cefalea tensional y la migraña, reduciendo el uso de medicación y también han mostrado efecto en la reducción de aspectos psicológicos como son la ansiedad y la depresión, muy presentes en este tipo de pacientes. Uno de los valores añadidos que presentan estas opciones de tratamiento es que se asocian con la plasticidad cerebral, lo cual también es esencial para mejorar en el progreso terapéutico.

En el estudio de Shiri y colaboradores, presentaron un novedoso sistema de realidad virtual que empleaba de manera simultánea el biofeedback con imágenes positivas y de sí mismos, sin dolor, a través de la realidad virtual con el objetivo de crear entornos virtuales sin dolor.

En este estudio, la muestra estaba compuesta por niños y adolescentes entre 10 y 18 años (la media fue de 13.4 años), 3 participantes de género femenino y 7 de género masculino, diagnosticados de cefalea tensional crónica y migraña crónica por un neurólogo, la duración de los síntomas variaba desde los 3 meses hasta los 5 años y medio (la media fue de 29,1 meses) y la medicación que tomaban eran principalmente analgésicos y antiinflamatorios. Durante el estudio no se retiró el tratamiento farmacológico que seguían los participantes ni tampoco se iniciaron tratamientos con nuevos fármacos. Todos los participantes cumplían con los criterios de inclusión marcados en el estudio y tanto ellos como sus padres dieron su consentimiento para participar en el estudio.

La presentación visual se basó en un conjunto de imágenes adquiridas del niño con diferentes expresiones faciales que comprendía desde el estado máximo de felicidad hasta el estado de máximo de tristeza o enfado, todas ellas se presentaron junto con un gráfico donde se representaba el dolor asociado a cada uno de los estados.

Durante la sesión se le mostraban al participante las imágenes, basadas

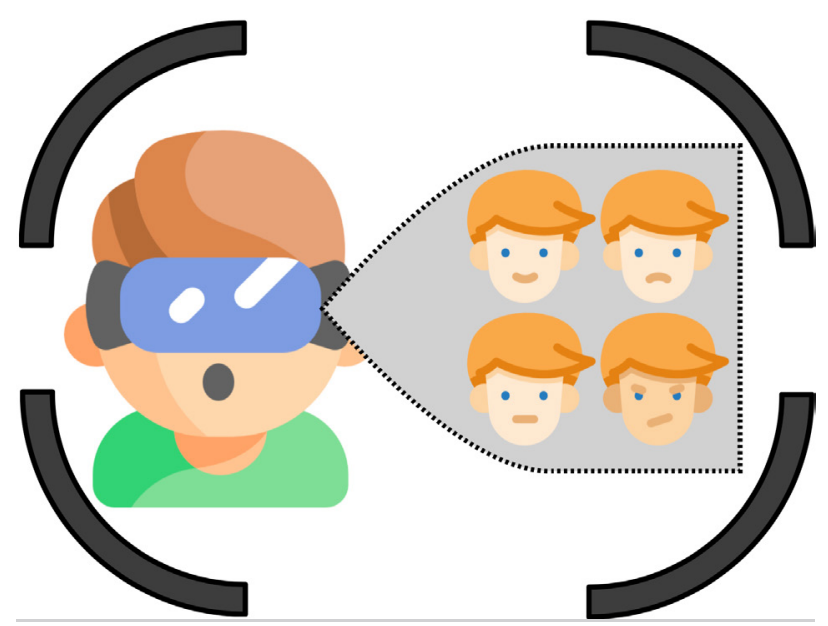

"Efectividad de la realidad virtual y el biofeedback en la población infantil con cefaleas de tipo crónico para disminuir el dolor y mejorar la calidad de vida " 
en los 5 estados emocionales, con el objetivo de conducirlo a un estado relajado y conseguir así una disminución del dolor.

Las variables que se registraron fueron el dolor, que se midió mediante la escala visual analógica; la calidad de vida, se utilizó el cuestionario pediátrico de calidad de vida, el cual evalúa aspectos físicos, sociales y emocionales. También se evaluó el estado de satisfacción de los participantes con la opción terapéutica que se empleó.

Todos estos datos fueron registrados antes de la intervención, al finalizarla, y se estableció un periodo de seguimiento al mes y a los 3 meses de haber finalizado la intervención.

Los resultados que se obtuvieron con respecto a la escala visual analógica fueron que, desde la medición basal hasta el último seguimiento, disminuyó la puntuación en 3.37 puntos. Con respecto a la calidad de vida,
"La realidad virtual junto con el biofeedback se establecen como una opción de tratamiento válida y muy bien valorado por los usuarios"

también se consideró un cambio significativo debido a que la puntuación disminuyó en casi 10 puntos con respecto a la evaluación inicial. En una escala de 1-5 los participantes valoraron con un 4.9 la satisfacción con respecto al uso de este trata-miento.

\section{Conclusión:}

El estudio que se ha comentado anteriormente concluye que la realidad virtual y el biofeedback son opciones de tratamiento beneficiosas para los niños afectos de cefaleas de tipo crónico. Se ha observado que disminuye el dolor, mejora la calidad de vida y además ha sido valorado como "muy bueno" por los mismos participantes del estudio. Se abre así una nueva vía de investigación para el tratamiento de esta patología en la que los pacientes muestran claramente una disminución de la calidad de vida unida a alteraciones de tipo psicosocial como puede ser la ansiedad, el estrés y la depresión.

\section{Sobre este artículo:}

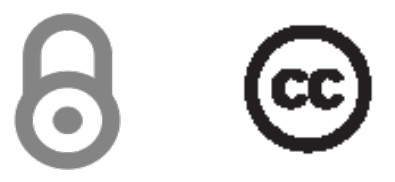

\section{Fuente /s:}

- Shiri S, Feintuch U, Weiss N, Pustilnik A, Geffen T, Kay B, et al. A Virtual Reality System Combined with Biofeedback for Treating Pediatric Chronic Headache-A Pilot Study. Pain Med. 2013;14:621-627.

- Kernick D, Reinhold D, Campbell JL. Impact of headache on young people in a school population. Br J Gen Pract. 2009;59:678-81.

- Damen L, Bruijn JK, Verhagen AP, et al. Symptomatic treatment of migraine in children: A systematic review of medication trials. Pediatrics 2005;116:e295302.

- Trautmann E, Lackschewitz H, Kröner-Herwig B. Psychological treatment of recurrent headache in children and adolescents-A meta-analysis. Cephalalgia 2006; 26:1411-26

Fuente de la Imagen: imagen de NeuroRehabnews.com con fines unicamente ilustrativos.

Para citra este artículo: Garrigós-Pedrón, M. Uso de la Realidad Virtual y el Biofeedback en niños con cefalea crónica. NeuroRehab News 2019 feb; 3(1):e0059.

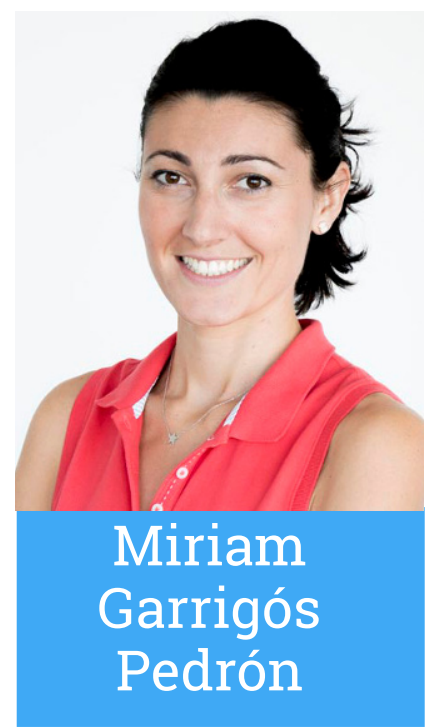

